\title{
BMJ
}

\section{Effect of retirement on major chronic conditions and fatigue: French GAZEL occupational cohort study}

\begin{abstract}
Hugo Westerlund, associate professor of psychology, ${ }^{1,2}$ Jussi Vahtera, professor of public health,, ${ }^{3,4}$ Jane $E$ Ferrie, senior research fellow, ${ }^{2}$ Archana Singh-Manoux, research director, ${ }^{2,5}$ Jaana Pentti, statistician, ${ }^{3}$ Maria Melchior, senior researcher, ${ }^{5}$ Constanze Leineweber, researcher, ${ }^{1}$ Markus Jokela, senior research fellow, ${ }^{2}$ Johannes Siegrist, professor of medical sociology, ${ }^{6}$ Marcel Goldberg, professor of epidemiology, ${ }^{5}$ Marie Zins, senior researcher, ${ }^{5}$ Mika Kivimäki, professor of social epidemiology ${ }^{2,3}$
\end{abstract}

\section{ABSTRACT}

Objectives To determine, using longitudinal analyses, if retirement is followed by a change in the risk of incident chronic diseases, depressive symptoms, and fatigue. Design Prospective study with repeat measures from 7 years before to 7 years after retirement.

Setting Large French occupational cohort (the GAZEL study), 1989-2007.

Participants 11246 men and 2858 women.

Main outcome measures Respiratory disease, diabetes, coronary heart disease and stroke, mental fatigue, and physical fatigue, measured annually by self report over the 15 year observation period; depressive symptoms measured at four time points.

Results The average number of repeat measurements per participant was 12.1. Repeated measures logistic regression with generalised estimating equations showed that the cumulative prevalence of self reported respiratory disease, diabetes, and coronary heart disease and stroke increased with age, with no break in the trend around retirement. In contrast, retirement was associated with a substantial decrease in the prevalence of both mental fatigue (odds ratio for fatigue one year after versus one year before retirement $0.19,95 \%$ confidence interval 0.18 to 0.21$)$ and physical fatigue $(0.27,0.26$ to 0.30$)$. A major decrease was also observed in depressive symptoms $(0.60,0.53$ to 0.67$)$. The decrease in fatigue around retirement was more pronounced among people with a chronic disease before retirement.

Conclusions Longitudinal modelling of repeat data showed that retirement did not change the risk of major chronic diseases but was associated with a substantial reduction in mental and physical fatigue and depressive symptoms, particularly among people with chronic diseases.

\section{INTRODUCTION}

Retirement is a major life transition that affects daily activities, social relationships, and income and is believed to have important consequences for health. However, empirical evidence on its effects on health remains inconsistent. Some studies have suggested a beneficial effect, at least in some groups, others an adverse effect, and still others no effect of retirement on health. ${ }^{2-12}$ This lack of consistent evidence is problematic given the drive to raise the retirement age in most developed countries. ${ }^{1}$

A major source of inconsistencies in the evidence is methodology. As the prevalence of several chronic and degenerative diseases increases with age, distinguishing the health effects of retirement from those of age is difficult. Fortunately, recent developments in longitudinal modelling provide an opportunity to overcome this problem if multiple repeated measurements of health both before and after retirement are available. Observations of longitudinal health trajectories that change at retirement would support a link between retirement and health, whereas stable health trajectories that continue without a break around retirement would suggest that such a link is unlikely.

In this 15 year longitudinal analysis of repeated health measurements, we examined the cumulative prevalence of self reported coronary heart disease and stroke, diabetes, and respiratory disease for each of the seven years before retirement through to seven years after statutory retirement. We also used yearly measurements to assess trajectories of fatigue and depressive symptoms during that period, as these states are commonly presented in clinical practice and known to be associated with the burden of work, disease, and mortality. ${ }^{13-22}$ To determine the effect of retirement on health, we sought to examine whether any change in these trajectories occurs at retirement.

\section{METHODS}

Study population

The GAZEL cohort was established in 1989 and comprises employees of the French national gas and electricity company: Electricité de France-Gaz de France (EDF-GDF). ${ }^{23}$ At baseline, 20624 employees $(73 \%$ men) aged 35-50 gave consent to participate. EDFGDF employees hold civil servant-like status that entails job security and good opportunities for occupational mobility. Typically, employees are hired when they 
are in their 20 s and stay with the company until retirement. Information on the health of the GAZEL participants is collected by annual surveys and registers.

In this study, we analysed data from GAZEL participants who retired between 1990 and 2006, inclusive. Of all 18884 retirees, we restricted inclusion in the study to those who did not retire on health grounds and who also returned a questionnaire at least once during the seven years before and at least once during the seven years after the year in which they retired. Thus, the sample analysed consisted of 14104 employees (11246 men and 2858 women) who retired at a mean age of 54.8 (SD 2.7) years (fig 1).

\section{Ascertainment of retirement}

Data on official date of retirement, longstanding illness or disability, and sickness absence came from company records. Because all retirement pensions are paid by EDF-GDF, company data on retirement are comprehensive and accurate, and less than $1 \%$ of the participants were lost to follow-up between 1989 and $2008 .^{24}$ The statutory age of retirement is nominally between 55 and 60 years, depending on job type. For example, the longer an employee has worked in a blue collar setting, the earlier he or she is allowed to retire. In the 1990s and early 2000s, a French government policy allowed public sector employees to retire three to five years earlier on a nearly full pension, further lowering the de facto statutory retirement age, and some workers can retire even earlier (for example, women with three or more children can retire after 15 years of service). Retirement on health grounds can be granted in the event of longstanding illness or disability.

We defined the year and type of retirement according to the first of the following events: receipt of an official retirement pension (statutory retirement), longstanding illness or disability, or more than 650 days of sickness absence in two consecutive years. We excluded participants who retired because of longstanding illness or disability or through prolonged sickness absence $(n=610)$

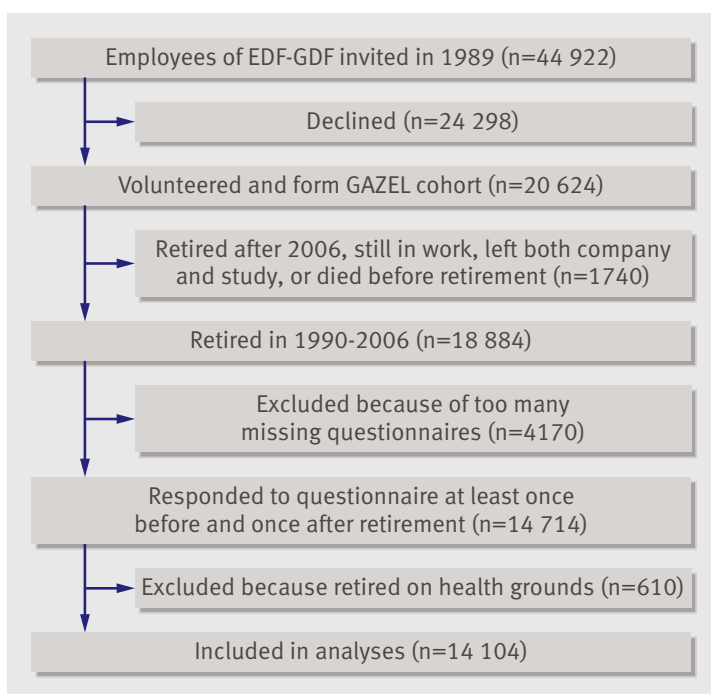

Fig 1| Flow chart describing selection of participants in study from the analytic sample, as previous research has found that health trajectories for these groups are very different from those of other retirees. ${ }^{2526}$ We divided age at retirement into categories of 54 years or under, 55 years, and 56 years or over.

\section{Fatigue and depressive symptoms}

We assessed mental and physical fatigue by using measures included in the annual questionnaires sent to all participants each January from 1989 to 2007. ${ }^{23}$ The questions were "Are you currently physically tired (French: fatigué(e))?" and "Are you currently mentally tired?" These questions used eight point visual analogue scales scored from 1 (not at all tired) to 8 (very tired). To identify participants with fatigue, we dichotomised the response scores at approximately the upper quintile (scores 6-8). We used all annual measurements in a 15 year time window from the seventh year preceding retirement to the seventh year after retirement.

We measured depressive symptoms by using the Center for Epidemiological Studies-Depression (CES-D) scale in 1996, 1999, 2002, and 2005. ${ }^{27}$ This scale includes 20 items with four response options (coded 0 to 3 ) that describe symptoms and behaviours characteristic of depressive disorder. Following previous research on validation of the French version of the CES-D, we considered a score of 17 or higher for men and 23 or higher for women to indicate depressive symptoms and possible clinical depression. ${ }^{2829}$

\section{Chronic diseases}

We used a checklist of various illnesses included in each yearly questionnaire to assess the cumulative prevalence of chronic diseases: coronary heart disease or stroke (defined as the presence of self reported angina, myocardial infarction, or stroke), respiratory disease (chronic bronchitis or asthma), and diabetes. These measures have been validated against medically certified sickness absence records, indicating variable under-reporting, which, however, is less pronounced for severe and disabling diseases such as those studied here. ${ }^{30}$ We considered that participants had a chronic disease if they ticked that disease in the year in question or had ticked that disease in any of the years before, going back to the seventh year before retirement. We considered that participants had a particular chronic disease if they ticked that disease in the year in question. As no response option existed for "not having a disease," we interpreted absence of a tick as absence of the disease in all years before the first ticking of the disease and as presence of the disease in all years after the disease was ticked. However, we imputed no values before the year of the first and after the year of the last returned questionnaire within the 15 year time window.

\section{Covariates}

Demographic factors included were sex, year of birth, and marital status (last reported before retirement). We derived occupational category immediately before retirement from company records and classified them into three grades: high (managers), intermediate (technical staff, line managers, and administrative associate 

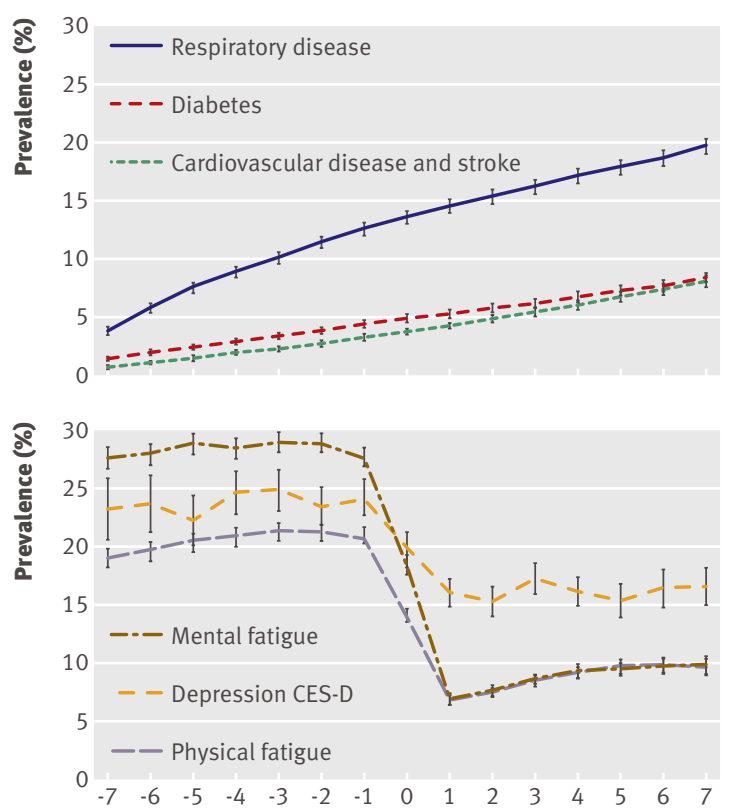

Years

Fig 2 | Trajectories of health in relation to retirement. Top panel shows prevalence of chronic diseases; bottom panel shows prevalence trajectories for mental and physical fatigue and depressive symptoms by year (year 0 is year of retirement). Trajectories are adjusted for time period. Wider confidence intervals for depression are result of only four measurement points as opposed to 15 for other variables; prevalences could be estimated for all years as retirement could occur in any year

professionals), and low (clerical and manual workers), on the basis of categorisations from the French National Institute of Statistics and Economic Studies (www.insee.fr/en).

\section{Statistical methods}

We based the analysis on a 15 year observation window, with the year of retirement as year 0 and a seven year observation period both before (years -7 to -1 ) and after retirement (years +1 to +7 ). To study the associations between potential explanatory variables and fatigue in year -1 , we used logistic regression analyses adjusted, where appropriate, for sex, age at retirement, occupational grade, and time of data collection (1989-99 v 2000-7).

To examine changes in the likelihood of fatigue, depressive symptoms, and chronic disease, we applied a repeated measures logistic regression analysis by using the generalised estimating equations method with autoregressive correlation structure, as in our earlier papers. ${ }^{2526}$ This method is not sensitive to missing measurements. We calculated the annual odds of these conditions and their 95\% confidence intervals adjusted for time of data collection. To plot trajectories of the cumulative prevalence of chronic diseases and the annual prevalence of mental and physical fatigue and depressive symptoms in relation to retirement, we transformed the odds to prevalence estimates.

We tested the effects of potential modifying variables on the shape of the trajectories for mental and physical fatigue in relation to retirement by entering the interaction term variable* year. The first step examined overall differences in the trajectory across the entire observation period (from year -7 to year +7 ) between groups defined by the modifying variables in year -1 (men $v$ women, people $<55 v 55 v>55$ at retirement, occupational groups, marital status, and people with $v$ without a chronic condition). In the next step, to illustrate these differences, we calculated the odds ratios of fatigue for year -1 versus year -7 , year +1 versus -1 , and +7 versus +1 , for different levels of the modifying variables in year -1 , using contrasts in the regression models. As the prevalence of fatigue was significantly higher before retirement among people with chronic conditions, the multiplicative interaction terms used in logistic regression do not preclude an additive interaction. Therefore, we also calculated the synergy index to explore the additive interaction between work and chronic conditions on fatigue ${ }^{3132}$ using the algorithm provided by Andersson and colleagues. ${ }^{33}$ The synergy index is equal to the calculation of $(\mathrm{OR}(\mathrm{AB})-1) /((\mathrm{OR}(\mathrm{Ab})-1)+(\mathrm{OR}(\mathrm{aB})-1))$, where $\mathrm{A}$ and $\mathrm{B}$ denote the presence of the two risk factors and $\mathrm{a}$ and $\mathrm{b}$ are designated as the absence of the risk factors. A synergy index of 1.0 implies perfect additivity and $>1$ indicates a synergistic interaction. We used SAS 9.2 for Windows for the analyses.

\section{RESULTS}

\section{Cohort characteristics}

Most of the 14104 participants were male (11246; $80 \%)$, married (12 589; 89\%), and, during the observation period, belonged to higher $(4781 ; 34 \%)$ or intermediate $(7654 ; 54 \%)$ employment grades, as a result of upward social mobility within the company (web table A). All the participants included in this study retired on a statutory basis. Of these, $10216(72 \%)$ retired between

\section{Table 1 |Number of observations per year}

\begin{tabular}{|c|c|c|c|c|}
\hline \multirow[b]{2}{*}{ Year } & \multicolumn{4}{|c|}{ No of observations } \\
\hline & $\begin{array}{l}\text { Mental } \\
\text { fatigue }\end{array}$ & $\begin{array}{l}\text { Physical } \\
\text { fatigue }\end{array}$ & $\begin{array}{l}\text { Depressive } \\
\text { symptoms }\end{array}$ & $\begin{array}{c}\text { Chronic } \\
\text { conditions* }\end{array}$ \\
\hline-7 & 10339 & 10390 & 1008 & 10471 \\
\hline-6 & 11067 & 11053 & 1227 & 11884 \\
\hline-5 & 11455 & 11455 & 1492 & 12655 \\
\hline-4 & 11354 & 11357 & 2226 & 12878 \\
\hline-3 & 11825 & 11832 & 2463 & 13577 \\
\hline-2 & 11958 & 11967 & 2729 & 13894 \\
\hline-1 & 12050 & 12059 & 2903 & 14104 \\
\hline 0 & 12076 & 12091 & 3137 & 14104 \\
\hline 1 & 12524 & 12537 & 3527 & 14104 \\
\hline 2 & 12315 & 12328 & 3186 & 13597 \\
\hline 3 & 12067 & 12091 & 3205 & 13183 \\
\hline 4 & 11748 & 11768 & 3678 & 12622 \\
\hline 5 & 10706 & 10718 & 2547 & 11512 \\
\hline 6 & 9426 & 9448 & 2156 & 10098 \\
\hline 7 & 7967 & 7972 & 2386 & 8477 \\
\hline
\end{tabular}

*Number of person years with any of respiratory disease, diabetes, or coronary heart disease/stroke (assessments carried forward between first and last measurement if missing in particular year). 
Table 2 |Change in fatigue by sociodemographic characteristics and health status before retirement, estimated with generalised estimating equations models

\begin{tabular}{|c|c|c|c|c|c|c|c|}
\hline \multirow[b]{3}{*}{ Pre-retirement characteristics* } & \multirow[b]{3}{*}{ No (\%) } & \multicolumn{6}{|c|}{ Odds ratios $(95 \% \mathrm{Cl})$} \\
\hline & & \multicolumn{3}{|c|}{ Change in risk of mental fatigue over time } & \multicolumn{3}{|c|}{ Change in risk of physical fatigue over time } \\
\hline & & Year $-1 v$ year -7 & Year $+1 v$ year -1 & Year $+7 v$ year +1 & Year $-1 v$ year -7 & Year $+1 v$ year -1 & Year $+7 v$ year +1 \\
\hline Sex: & & \multicolumn{3}{|c|}{$P<0.0001 \dagger$} & \multicolumn{3}{|c|}{$P=0.1006 \dagger$} \\
\hline Male & $11246(80)$ & $1.00(0.94$ to 1.06$)$ & $0.18(0.16$ to 0.20$)$ & $1.48(1.32$ to 1.66$)$ & 1.14 (1.07 to 1.22$)$ & $0.29(0.26$ to 0.32$)$ & $1.51(1.35$ to 1.69$)$ \\
\hline Female & $2858(20)$ & $1.06(0.95$ to 1.18$)$ & 0.24 (0.21 to 0.28$)$ & $1.56(1.30$ to 1.88$)$ & $1.16(1.03$ to 1.30$)$ & 0.24 (0.21 to 0.27$)$ & $1.45(1.20$ to 1.76$)$ \\
\hline \multicolumn{2}{|l|}{ Age at retirement: } & \multicolumn{3}{|c|}{$P<0.0001 \dagger$} & \multicolumn{3}{|c|}{ P<0.0001† } \\
\hline$\langle 55$ years & $5348(38)$ & 1.08 (1.00 to 1.18$)$ & $0.15(0.14$ to 0.17$)$ & 1.54 (1.33 to 1.79$)$ & $1.13(1.02$ to 1.24$)$ & $0.22(0.20$ to 0.25$)$ & 1.61 (1.38 to 1.88$)$ \\
\hline 55 years & $4653(33)$ & $1.05(0.97$ to 1.15$)$ & $0.20(0.18$ to 0.23$)$ & $1.52(1.29$ to 1.80$)$ & 1.27 (1.15 to 1.41$)$ & $0.28(0.24$ to 0.32$)$ & $1.50(1.27$ to 1.77$)$ \\
\hline$>55$ years & 1654 (12) & $0.83(0.76$ to 0.91$)$ & $0.25(0.22$ to 0.29$)$ & 1.30 (1.07 to 1.59$)$ & 0.99 (0.89 to 1.09$)$ & 0.35 (0.31 to 0.40$)$ & $1.28(1.06$ to 1.54$)$ \\
\hline \multicolumn{2}{|l|}{ Employment grade: } & \multicolumn{3}{|c|}{$P<0.0001 \dagger$} & \multicolumn{3}{|c|}{$P=0.0446 \dagger$} \\
\hline Higher & $4781(34)$ & 0.85 (0.78 to 0.92$)$ & $0.19(0.17$ to 0.22$)$ & 1.28 (1.07 to 1.52$)$ & 1.02 (0.93 to 1.13$)$ & $0.29(0.25$ to 0.33$)$ & 1.36 (1.14 to 1.63$)$ \\
\hline Intermediate & 7654 (54) & $1.07(1.00$ to 1.15$)$ & $0.19(0.17$ to 0.21$)$ & $1.56(1.37$ to 1.77$)$ & 1.14 (1.06 to 1.24$)$ & $0.27(0.24$ to 0.30$)$ & $1.60(1.38$ to 1.78$)$ \\
\hline Lower & 1654 (12) & $1.26(1.08$ to 1.46$)$ & $0.21(0.17$ to 0.26$)$ & 1.47 (1.12 to 1.92$)$ & $1.26(1.06$ to 1.48$)$ & $0.26(0.21$ to 0.31$)$ & $1.22(0.85$ to 1.48$)$ \\
\hline \multicolumn{2}{|l|}{ Marital status: } & \multicolumn{3}{|c|}{$P=0.0061 \dagger$} & \multicolumn{3}{|c|}{$P=0.2746 \dagger$} \\
\hline Not married/cohabitating & $1511(11)$ & $0.87(0.75$ to 1.01$)$ & $0.27(0.22$ to 0.33$)$ & $1.57(1.22$ to 2.01$)$ & 1.14 (0.97 to 1.34$)$ & $0.29(0.24$ to 0.36$)$ & 1.48 (1.14 to 1.93$)$ \\
\hline Married or cohabitating & $12589(89)$ & $1.03(0.97$ to 1.08$)$ & 0.19 (0.17 to 0.20$)$ & 1.47 (1.32 to 1.63$)$ & 1.13 (1.06 to 1.21$)$ & $0.27(0.25$ to 0.29$)$ & 1.47 (1.32 to 1.63$)$ \\
\hline \multicolumn{2}{|l|}{ Respiratory diseaseł: } & \multicolumn{3}{|c|}{$\mathrm{P}=0.0994 \dagger$} & \multicolumn{3}{|c|}{$P=0.5701 \dagger$} \\
\hline No & $12334(87)$ & 1.03 (0.97 to 1.09$)$ & 0.19 (0.17 to 0.21$)$ & 1.48 (1.33 to 1.64$)$ & 1.16 (1.08 to 1.24$)$ & $0.27(0.25$ to 0.29$)$ & 1.47 (1.32 to 1.64$)$ \\
\hline Yes & 1770 (13) & 0.88 (0.77 to 1.00$)$ & $0.22(0.18$ to 0.27$)$ & 1.44 (1.14 to 1.82 ) & 1.02 (0.88 to 1.17$)$ & $0.30(0.25$ to 0.36$)$ & 1.40 (1.12 to 1.77$)$ \\
\hline \multicolumn{2}{|l|}{ Diabetesł: } & \multicolumn{3}{|c|}{$\mathrm{P}=0.0620 \dagger$} & \multicolumn{3}{|c|}{$\mathrm{P}=0.1940 \dagger$} \\
\hline No & $13487(96)$ & 1.01 (0.96 to 1.07$)$ & $0.19(0.18$ to 0.21$)$ & 1.48 (1.34 to 1.64$)$ & 1.13 (1.06 to 1.20$)$ & $0.27(0.25$ to 0.29$)$ & $1.47(1.32$ to 1.62$)$ \\
\hline Yes & $617(4)$ & 0.86 (0.69 to 1.06$)$ & 0.25 (0.19 to 0.34$)$ & 1.27 (0.87 to 1.85$)$ & 1.10 (0.85 to 1.41$)$ & $0.35(0.27$ to 0.47$)$ & 1.35 (0.97 to 1.89$)$ \\
\hline \multicolumn{2}{|l|}{ Coronary heart disease/strokeł: } & \multicolumn{3}{|c|}{$P=0.5428 \dagger$} & \multicolumn{3}{|c|}{$\mathrm{P}=0.1233 \dagger$} \\
\hline No & $13651(97)$ & 0.99 (0.94 to 1.05$)$ & $0.20(0.18$ to 0.21$)$ & $1.49(1.35$ to 1.65$)$ & 1.11 (1.04 to 1.18$)$ & $0.28(0.26$ to 0.30$)$ & 1.48 (1.34 to 1.64$)$ \\
\hline Yes & $453(3)$ & $1.39(1.07$ to 1.81$)$ & $0.17(0.12$ to 0.25$)$ & 1.00 (0.61 to 1.66$)$ & 1.67 (1.27 to 2.20$)$ & 0.24 (0.18 to 0.33$)$ & $1.10(0.71$ to 1.71$)$ \\
\hline \multicolumn{2}{|l|}{ Any chronic disease $£ \S:$} & \multicolumn{3}{|c|}{$P=0.3106 \dagger$} & \multicolumn{3}{|c|}{$P=0.2685 \dagger$} \\
\hline No & $11475(81)$ & $1.03(0.97$ to 1.09$)$ & $0.19(0.17$ to 0.20$)$ & 1.52 (1.36 to 1.70$)$ & 1.15 (1.08 to 1.24$)$ & $0.27(0.24$ to 0.29$)$ & 1.50 (1.34 to 1.69$)$ \\
\hline Yes, at least one & 2629 (19) & 0.93 (0.83 to 1.03$)$ & $0.22(0.19$ to 0.25$)$ & 1.33 (1.10 to 1.62$)$ & 1.07 (0.95 to 1.21$)$ & $0.30(0.26$ to 0.34$)$ & 1.36 (1.13 to 1.64$)$ \\
\hline $\begin{array}{l}{ }^{*} \text { Assessed at year }-1 \text { unless sta } \\
\text { Test of difference in fatigue tra } \\
\text { for interaction term "group } \\
\ddagger \text { *year. } \\
\ddagger \text { Reported in any of years }-7 \text { to }\end{array}$ & $\begin{array}{l}\text { wise. } \\
\text { cross who } \\
\text { tion to re }\end{array}$ & . $\quad . \quad 5$ & & & & 55 at retiremen & d so on); $P$ value is \\
\hline
\end{tabular}

the ages of 53 and 57 inclusive, and $13846(98 \%)$ retired between 50 and 60 years inclusive; by age 64 , all were retired (web figure A). In the year before retirement, $723 / 2903(25 \%)$ had depressive symptoms and 2629 $(19 \%)$ had prevalent respiratory disease, diabetes, or coronary heart disease/stroke.

The analyses were based on 168937 to 187160 observation years (on average 12.1 observations per person), except for depressive symptoms, which were not assessed yearly and for which 37870 observations were available (table 1).

\section{Trajectories of chronic disease, fatigue, and depression}

Figure 2 shows the estimated cumulative prevalence of the self reported chronic diseases (top panel) and the annual prevalence of fatigue and depressive symptoms (bottom panel) in relation to retirement. The cumulative prevalence of chronic disease increased with age, with no break in the trend around the time of retirement. In contrast, retirement was associated with a substantial decrease in the prevalence of mental fatigue (odds ratio for fatigue one year after versus one year before retirement $0.19,95 \%$ confidence interval
0.18 to 0.21$)$, physical fatigue $(0.27,0.26$ to 0.30$)$, and depressive symptoms $(0.60,0.53$ to 0.67$)$ (web table B), a pattern also evident in a sensitivity analysis using continuous indicators of these outcome variables. Further sensitivity analyses, based on the 3729 respondents who returned a questionnaire every year over the 15 year observation period, yielded very similar results for the post-retirement decline in fatigue and depression (web table B), suggesting that selective drop-out from the cohort is an unlikely explanation for our findings. ${ }^{34}$

The retirement related decrease in fatigue seemed to occur over a two year period around retirement (fig 2), which may reflect the fact that the survey is done every year in January, whereas retirement occurs throughout the year. In addition, some employees may have stopped working several months before their official retirement date as a result of accumulated periods of vacation not taken during their employment.

\section{Groups at risk of fatigue}

Both mental and physical fatigue immediately before retirement (in year -1 ) were more common among 

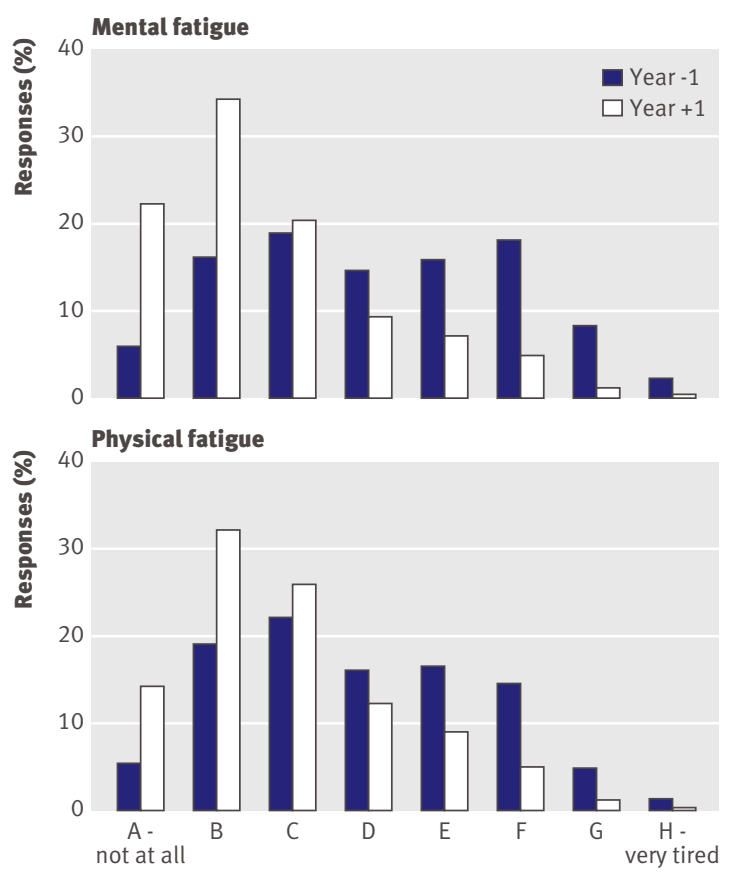

Fig 3 Comparison of distribution of responses to questions about mental and physical fatigue in year before and year after retirement

women, participants who retired before age 55, and those who had a chronic disease (web table A). Unmarried respondents and those in a low occupational grade had higher odds of physical (but not mental) fatigue.

Table 2 shows estimates for trajectories of fatigue by individual characteristics one year before retirement. As a first step, we tested the difference in trajectory of fatigue across the entire observation period from year -7 to year +7 between various groups defined by sociodemographic measures and diseases. For both mental and physical fatigue, these trajectories were different between men and women, age groups at retirement, employment grades, and marital status.

To illustrate these differences, we split the observation window into three parts and analysed change in fatigue over these three periods: the pre-retirement period (year -1 vyear -7 ), the transition to retirement (year +1 vyear -1 ), and the post-retirement period (year $+7 v$ year +1$)$. The decrease in mental fatigue around retirement (year -1 to +1 ) was larger in men, in participants who retired at age 55 or earlier, and in those who were married or cohabitating than among women, participants who retired at age 56 or older, and those who were single. Before retirement (year -7 to -1 ), the smallest increase in mental fatigue was in workers who retired after 55 years of age, worked in a high occupational grade, or were single compared with those who retired at 55 or earlier, worked in an intermediate or low occupational grade, or were married. After retirement (year +1 to +7 ), no significant differences in trajectory existed between these groups (table 2).

Regarding physical fatigue, the decrease around retirement (year -1 to +1 ) was larger in women and participants who retired earlier than among men and those who retired later. No increase in physical fatigue before retirement (year -7 to -1 ) was apparent among those who were older than 55 at retirement, whereas an increase occurred among those who retired at 55 or earlier. Employees in high employment grades had less increase in physical fatigue before retirement (year -7 to -1 ) than did those in intermediate or low grades. After retirement (year +1 to +7 ), those who had retired before the age of 55 had a steeper increase in physical fatigue than did those who had retired after 55 (table 2).

\section{Changes in fatigue in those with and without chronic conditions}

Table 2 also shows that in relative terms, changes in fatigue over time were similar among people with and without a chronic disease before retirement, as reflected in the non-significant multiplicative interaction terms. However, as the initial values for fatigue were very different between people with and without chronic conditions, substantial differences in absolute changes in fatigue can exist even if the multiplicative interaction terms are non-significant. We therefore used synergy indices to take into account absolute differences in the retirement related decrease in fatigue between these groups. These findings suggest that, in absolute terms, a substantially greater decrease in the prevalence of mental and physical fatigue at retirement occurred among people who had at least one chronic disease, in particular coronary heart disease or stroke or respiratory disease, compared with those who were disease free (web table $\mathrm{C}$ and fig $\mathrm{B}$ ).

\section{Shift in fatigue distribution after retirement}

Figure 3 shows the distributions of mental fatigue (top panel) and physical fatigue (bottom panel) in the years before $(-1)$ and after $(+1)$ retirement. Comparison of the pre-retirement and post-retirement responses shows a considerable shift from higher to lower fatigue scores over the whole range of the rating scale.

\section{DISCUSSION}

In a large occupational cohort based in France, retirement was associated with a substantial decrease in both mental and physical fatigue and with a smaller but clearly significant decrease in the prevalence of depressive symptoms. In contrast, we found no change in the trends for self reported coronary heart disease/stroke, respiratory disease, and diabetes in relation to retirement, although, as expected, the cumulative prevalence of these diseases gradually increased with age. These findings suggest that retirement affects mental and physical fatigue and depressive symptoms but does not directly affect the risk of major chronic diseases.

Several explanations of these findings are possible. If work is tiring for many older workers, the decrease in fatigue could simply reflect removal of the source of the problem. ${ }^{2526}$ Also, without the demands of work, participants may feel less concerned about limited energy, leading to lower ratings of fatigue. Furthermore, retirement may allow people more time to 


\section{WHAT IS ALREADY KNOWN ON THIS TOPIC}

Many governments in Europe are raising the retirement age to increase the proportion of the population in work

Retirement is a major social transition believed to have important consequences for health, but empirical evidence remains contradictory

A major research challenge is to distinguish the effect of retirement on health from the effects of age

\section{WHAT THIS STUDY ADDS}

Longitudinal modelling of repeat measurements for seven years before and seven years after retirement enabled the study to control for confounding by age

Retirement seemed not to change the risk of major chronic diseases

Retirement was associated with a substantial reduction in mental and physical fatigue and depressive symptoms, particularly among participants with chronic disease

engage in stimulating and restorative activities, such as physical exercise..$^{35}$

\section{Strengths and limitations}

A major strength of this study is that it is based on repeated yearly measurements over an extended time period in a stable occupational cohort. Although observational data cannot prove causality and rule out residual confounding, the findings provide unique evidence that retirement is related to improvement in wellbeing, with little effect on risk of chronic disease. As only participants who retired on a statutory basis were included in the analyses (we excluded employees who retired on health grounds), and as we saw improvements in all age groups, reverse causality through effects of fatigue on retirement is unlikely to have a major effect on the results.

The most salient limitation of this study is that the participants retired at 55 or close to that age, owing to generous retirement policies in France in general and EDF-GDF in particular. Thus, our findings may not apply to settings in which people retire later. Non-participation and drop-out also limit the generalisability of the results to all EDF-GDF employees, but as attrition may be higher in unhealthy people, ${ }^{24}$ who tended to gain more from retirement, this is unlikely to cause inflated results. The prevalence trajectories for chronic diseases were based on self reported conditions within the 15 year observation window. This may lead to underestimation, ${ }^{30}$ especially at the beginning of the observation window, as we interpreted lack of an affirmative response in the disease checklist (including non-response to a whole questionnaire in the intervening years) as absence of disease. The measures of fatigue used in the study have been validated only to a limited extent, ${ }^{19}$ and the findings on fatigue should therefore be interpreted with caution. The thresholds used for fatigue are arbitrary, but sensitivity analyses and examination of figure 3 show that the main results are not artefacts of dichotomisation. In contrast to other outcomes which were measured up to 15 times, depressive symptoms were measured in only four of the yearly questionnaires sent to the participants, yielding fewer person measurement observations. However, as retirement could occur in any year, we were able to estimate prevalences for all years in relation to retirement, although with greater uncertainty than for the other outcome measures.

\section{Comparison with other studies}

Reduction in fatigue and depression may explain the striking improvement in self reported health status after retirement previously reported for this cohort. ${ }^{2526}$ Improvement in perceived health after retirement has also been seen in cross sectional data from Sweden and in prospective data from the United Kingdom (the Whitehall II study). ${ }^{5637}$ In our study, people with self reported chronic disease, such as coronary heart disease/stroke, had a larger absolute decrease in fatigue in relation to retirement. Nevertheless, a substantial decrease in fatigue also occurred among those free of physical disease. This may indicate that not only people with underlying disease but also a large proportion of healthy workers in their last years of employment have high levels of work related fatigue, which seems to be largely relieved by retirement.

The finding that retirement seems to have no direct effect on chronic disease is in line with one of the very few prospective studies of retirement and physical health published to date. ${ }^{12}$ However, although retirement seems not to affect chronic disease directly, the decrease in fatigue could in turn have positive effects on future health over the long term or could be a marker of decreased risks of future diseases. For instance, fatigue could be related to increased risk of cardiovascular disease and death. ${ }^{202138}$

\section{Conclusions and policy implications}

The evidence in this paper suggests that retirement does not need special attention in relation to prevention of chronic disease. In contrast, we found that fatigue is common among older workers and that retirement is associated with a substantial reduction in mental and physical fatigue as well as depressive symptoms. This could have important implications for both policy makers and occupational health practitioners, given the major challenges of the ageing population. ${ }^{1}$ Our results indicate that fatigue may be an underlying reason for early exit from the labour market and decreased productivity and that redesign of work, healthcare interventions, or both may be necessary to enable a larger proportion of older people to work in full health. Future research should investigate the generalisability of the findings to other countries and settings.

We thank EDF-GDF, especially the Service Général de Médecine de Contrôle, and the "Caisse centrale d'action sociale du personnel des industries électrique et gazière." We also wish to acknowledge the Cohorts Team at Inserm Unit 1018 responsible for management of the GAZEL database and Stockholm Stress Centre for providing the basis for our international collaboration.

Contributors: HW, MK, and JV designed the original hypothesis. MG and MZ are the principal investigators of the Gazel Cohort Study and prepare the data. HW did all the analyses in close dialogue with MK and JV. MK and JV contributed equally to the study. JP provided statistical advice. HW wrote the first draft of the report. All authors interpreted the results, revised the text, and approved the final draft of the report. All authors had full access to all of the data in the study. HW is the guarantor. 
Funding: $\mathrm{HW}$ and $\mathrm{CL}$ are supported by the Swedish Council for Working Life and Social Research (FAS, grants \#2004-2021, \#2007-1143, and \#2009-1758), JV and MK are supported by the Academy of Finland (grants \#124271, \#124322, \#129262, and \#132944), MK is additionally supported by a BUPA Foundation UK specialist research grant and the National Institutes of Health/National Heart, Lung, and Blood Institute (NIH) (R01HL036310-20A2). MK and AS-M are supported by the National Institute on Aging, NIH (R01AG013196; R01AG034454); AS-M is also supported by a EUYRI award from the European Science Foundation. This work was additionally supported by a grant from the ESRC Research Seminar Series Competition 2007/8 (RES-451-26- 0491). The GAZEL Cohort Study was funded by EDF-GDF and INSERM and received grants from the "Cohortes Santé TGIR Program," Agence nationale de la recherché (ANR), and Agence française de sécurité sanitaire de l'environnement et du travail (AFSSET). The study sponsors did not contribute to the study design and had no role in the conduct of the study, data collection, data management, data analysis, or interpretation of the data, nor in the preparation, review, or approval of the manuscript. Competing interests: All authors have completed the Unified Competing Interest form at www.icmje.org/coi_disclosure.pdf (available on request from the corresponding author) and declare that (1) regarding the submitted work HW and CL have support from the Swedish Council for Working Life and Social Research (FAS); IV and MK have support from the Academy of Finland; MK has additional support from the BU

PA Foundation, UK; MK and AS-M also have support from the National Institutes of Health (NIH), USA; AS-M has additional support from the European Science Foundation (ESF); JF and all other authors except IS have additional support from ESRC, UK; MG and MZ have additional support from the Institut de recherche en santé publique (INSERM) and Caisse centrale d'action sociale, France; and JS had support from Agence nationale de la recherché (ANR), France; (2) none of the authors have any relationships with any company or organisation that might have an interest in the submitted work in the previous 3 years; (3) their spouses, partners, or children have no financial relationships that may be relevant to the submitted work; and (4) the authors have no non-financial interests that may be relevant to the submitted work."

Ethical approval: The GAZEL study received approval from the national commission overseeing ethical data collection in France ("Commission Nationale de L'Informatique et Libertés"), GAZEL \#105 728-Avis du 26 avril 1988. In addition, we also had the approval of the Ethics Evaluation Committee of INSERM (the French Institute of Medical Research and Health), opinion number 01-017, 20 May 2009.

Data sharing: The statistical script is available from the corresponding author at hugo.westerlund@stress.su.se; the dataset can be requested from the principal investigators of the GAZEL study at Marie.Zins@inserm.fr.

1 Doyle Y, McKee M, Rechel B, Grundy E. Meeting the challenge of population ageing. $B M J$ 2009;339:b3926.

2 Mojon-Azzi S, Sousa-Poza A, Widmer R. The effect of retirement on health: a panel analysis using data from the Swiss Household Panel. Swiss Med Wkly 2007;137:581-5.

3 Drentea P. Retirement and mental health. J Aging Health 2002;14:167-94.

4 Gall TL, Evans DR, Howard J. The retirement adjustment process: changes in the well-being of male retirees across time. J Gerontol B Psychol Sci Soc Sci 1997:52:110-7.

5 Mein G, Martikainen P, Hemingway H, Stansfeld S, Marmot M. Is retirement good or bad for mental and physical health functioning? Whitehall II longitudinal study of civil servants. J Epidemiol Community Health 2003:57:46-9.

6 Buxton JW, Singleton N, Melzer D. The mental health of early retirees -national interview survey in Britain. Soc Psychiatry Psychiatr Epidemiol 2005; 40:99-105.

7 Bosse R, Aldwin CM, Levenson MR, Ekerdt DJ. Mental health differences among retirees and workers: findings from the Normative Aging Study. Psychol Aging 1987;2:383-9.

8 Alavinia SM, Burdorf A. Unemployment and retirement and ill-health: a cross-sectional analysis across European countries. Int Arch Occup Environ Health 2008;82:39-45.

9 Butterworth P, Gill SC, Rodgers B, Anstey KJ, Villamil E, Melzer D. Retirement and mental health: analysis of the Australian national survey of mental health and well-being. Soc Sci Med 2006;62:1179-91

10 Villamil E, Huppert FA, Melzer D. Low prevalence of depression and anxiety is linked to statutory retirement ages rather than personal work exit: a national survey. Psychol Med 2006;36:999-1009.

11 Van Solinge H. Health change in retirement: a longitudinal study among older workers in the Netherlands. Res Aging 2007;29:225-56.
12 Ekerdt DJ, Baden L, Bosse R, Dibbs E. The effect of retirement on physical health. Am J Public Health 1983;73:779-83.

13 Moncrieff G, Fletcher J. Tiredness. BMJ 2007:334:1221.

14 De Raeve L, Vasse RM, Jansen NW, van den Brandt PA, Kant I. Mental health effects of changes in psychosocial work characteristics: a prospective cohort study. I Occup Environ Med 2007:49:890-9.

15 Fahlen G, Knutsson A, Peter R, Akerstedt T, Nordin M, Alfredsson L, et al. Effort-reward imbalance, sleep disturbances and fatigue. Int Arch Occup Environ Health 2006;79:371-8.

16 Magnusson Hanson LL, Theorell T, Bech P, Rugulies R, Burr M, Hyde M, et al. Psychosocial working conditions and depressive symptoms among Swedish employees. Int Arch Occup Environ Health 2009;82:951-60.

17 De Lange AH, Kompier MA, Taris TW, Geurts SA, Beckers DG, Houtman IL, et al. A hard day's night: a longitudinal study on the relationships among job demands and job control, sleep quality and fatigue. / Sleep Res 2009;18:374-83.

18 Bultmann U, Kant IJ, Schroer CA, Kasl SV. The relationship between psychosocial work characteristics and fatigue and psychological distress. Int Arch Occup Environ Health 2002;75:259-66.

19 Goldberg P, Gueguen A, Schmaus A, Nakache JP, Goldberg M. Longitudinal study of associations between perceived health status and self reported diseases in the French Gazel cohort. J Epidemiol Community Health 2001;55:233-8.

20 Avlund K, Schultz-Larsen K, Davidsen M. Tiredness in daily activities at age 70 as a predictor of mortality during the next 10 years. / Clin Epidemiol 1998:51:323-33.

21 Hardy SE, Studenski SA. Fatigue predicts mortality in older adults. J Am Geriatr Soc 2008;56:1910-4.

22 Gump BB, Matthews KA, Eberly LE, Chang YF. Depressive symptoms and mortality in men: results from the Multiple Risk Factor Intervention Trial. Stroke 2005;36:98-102.

23 Goldberg M, Leclerc A, Bonenfant S, Chastang JF, Schmaus A, Kaniewski N, et al. Cohort profile: the GAZEL Cohort Study. Int Epidemiol 2007;36:32-9.

24 Goldberg M, Chastang JF, Zins M, Niedhammer I, Leclerc A. Health problems were the strongest predictors of attrition during follow-up of the GAZEL cohort. / Clin Epidemiol 2006;59:1213-21.

25 Westerlund H, Kivimaki M, Singh-Manoux A, Melchior M, Ferrie JE, Pentti I, et al. Self-rated health before and after retirement in France (GAZEL): a cohort study. Lancet 2009;374:1889-96.

26 Vahtera J, Westerlund H, Hall M, Sjosten N, Kivimaki M, Salo P, et al. Effect of retirement on sleep disturbances: the GAZEL prospective cohort study. Sleep 2009;32:1459-66.

27 Radloff $L$. The CES-D scale: a self report depression scale for research in the general population. Appl Psychol Meas 1977;1:385-401.

28 Melchior M, Ferrie J, Alexanderson K, Goldberg M, Kivimaki M, Singh-Manoux A, et al. Using sickness absence records to predict future depression in a working population: prospective findings from the GAZEL cohort. Am J Public Health 2009;99:1417-22.

29 Fuhrer R, Rouillon F. La version française de l'échelle CES-D (Center for Epidemiologic Studies-Depression Scale): description et traduction de l'échelle d'autoévaluation. Psychiatr Psychobiol 1989;4:163-66.

30 Metzger MH, Goldberg M, Chastang JF, Leclerc A, Zins M. Factors associated with self-reporting of chronic health problems in the French GAZEL cohort. / Clin Epidemiol 2002;55:48-59.

31 Rothman KJ. Epidemiology: an introduction. Oxford University Press, 2002.

32 Hosmer DW, Lemeshow S. Confidence interval estimation of interaction. Epidemiology 1992;3:452-6.

33 Andersson T, Alfredsson L, Kallberg H, Zdravkovic S, Ahlbom A. Calculating measures of biological interaction. Eur J Epidemiol 2005;20:575-9.

34 Goldberg M, Chastang JF, Leclerc A, Zins M, Bonenfant S, Bugel I, et al. Socioeconomic, demographic, occupational, and health factors associated with participation in a long-term epidemiologic survey: a prospective study of the French GAZEL cohort and its target population. Am J Epidemiol 2001;154:373-84.

35 Evenson KR, Rosamond WD, Cai J, Diez-Roux AV, Brancati FL. Influence of retirement on leisure-time physical activity: the atherosclerosis risk in communities study. Am J Epidemiol 2002;155:692-9.

36 Vogel J, Theorell T. Social welfare models, labor markets, and health outcomes. In: Heymann J, Hertzman C, Barer ML, Evans RG, eds. Healthier societies: from analysis to action. Oxford University Press, 2006:267-95.

37 Jokela M, Ferrie JE, Gimeno D, Chandola T, Shipley M, Head J, et al. Retirement and trajectories of mental health and physical functioning from midlife to early old age: the Whitehall II prospective cohort study. Epidemiology 2010;21:284-90.

38 Melamed S, Shirom A, Toker S, Berliner S, Shapira I. Burnout and risk of cardiovascular disease: evidence, possible causal paths, and promising research directions. Psychol Bull 2006;132:327-53.

Accepted: 8 September 2010 